\title{
Green Practices of Theme Parks towards Tourism Sustainability of Subic Bay Freeport Zone
}

\author{
Dr. Eric A. Matriano ${ }^{1}$, Dr. Rowena F. Shabazz ${ }^{1}$, Dr. Salvacion A. Nihei ${ }^{1}$ and Ms. Merleen Labis ${ }^{1}$ \\ ${ }^{1}$ Columban College, Inc., Philippines
}

\begin{abstract}
Promoting sustainability as a result of globalization in tourism sector is a growing demand. Green practices are necessary for a balanced and healthy economy while protecting and enhancing the socio-cultural, historical, natural and built-resources for the enjoyment and well-being of all stakeholders of the theme parks. This is a descriptive-survey on green practices in response to tourism sustainability of three (3) selected theme parks in Subic Bay Freeport Zone. Participants were managers, employees and customers who were purposively selected. Data were gathered through in-depth interview and survey-checklist and observation of practices. Findings reveal that the theme parks comply with the minimum environmental requirements but still need to enhance green practices in terms of greenhouse gas reduction, solid wastes management, freshwater consumption reduction, waste water management, energy conservation, biodiversity and ecosystem conservation, land use planning and management, providing economic benefits and preserving the social norms and cultures of local communities, and environmental training and education of employees.
\end{abstract}

Keywords: tourism, green practices, theme parks, tourism sustainability, descriptive-survey, SBFZ

\section{Introduction}

Tourism is one of the world's largest industries. The World Travel and Tourism Council (WTTC) estimates that tourism generates some $12 \%$ of the world total GNP [1]. With studies predicting continued growth, tourism is an increasingly important factor in the planning and management for country's overall sustainability.

Tourists are becoming more interested in environmental protection or green practices. Consumers are increasingly considering environmental quality as well as the quality of services as factors in their selection of tourist destinations. More and more consumers want a high standard of environmental conservation coupled with simple, efficient and pleasant service. It appears that many tourists now prefer safe, unspoiled and uncrowded destinations.

All tourism and recreation activities lead to environmental and social change. Knowledge of the causes of tourism impacts and problems aids decision-making and fosters more effective management actions. A basic knowledge of the range of impacts can also aid planning and generate a useful checklist for developing tourism monitoring indicators, essential for determining whether management objectives are being met.

\section{Objective of the Study}

The study focused on descriptive survey of green practices of three (3) theme parks at Subic Bay Freeport Zone (SBFZ) and its implications towards tourism sustainability. Managers, employees and customers of Ocean Adventure, Treetop Adventure and Zoobic Zafari were the respondents who provided the data needed to answer the following questions: (1) How do the participants describe the green practices of the theme parks in terms of (a) greenhouse gas emission management and reduction, (b) solid waste management, reduction, reuse and recycling, (c) freshwater consumption reduction, (d) wastewater management, (e) energy efficiency, conservation and management, (f) ecosystem and biodiversity conservation, (g) land use planning and management, (h) air quality protection, (i) noise reduction, and (j) responsible purchasing?; (2) How do the theme parks preserve the social norms and cultures of local and indigenous communities as well as provide economic benefits?; (3) What training and education do they provide for employees and customers?; and (4) What are the implications of the findings towards tourism sustainability?

Green practices of three major theme park attractions situated in Subic Bay Freeport Zone (SBFZ) were analyzed towards tourism sustainability of the place. (1) Treetop Adventure where tourists are coming from all points of the globe to experience one of the most exciting adventure tourism activities around. It is a one-of-a- 
kind nature and adrenaline experience through the native rainforest of Subic with zip line, canopy ride, treetop fall adventures, among others; (2) Zoobic Safari Forest Adventure Park and Tiger Safari is an animal fun park that offers adventure of close contact experiences with exotic wildlife, go on a tiger safari and visit of crocodile kingdom; and (3) Ocean Adventure is owned by a Philippine Corporation, known as Subic Bay Marine Exploratorium, along with Camayan Beach Resort. It is known for its advocacy in taking care of animals while providing educational entertainment for all ages such as dolphin and sea lion show, jungle animal encounter, and acrobatic shows.

\section{Methodology}

This is a descriptive-survey study on green practices in response to tourism sustainability of three (3) selected theme parks in Subic Bay Freeport Zone, namely Ocean Adventure, Treetop Adventure and Zoobic Zafari. Descriptive research is concerned with describing the characteristics of a particular individual, an institution, object or of a group [2]. It is concerned with: "conditions or relationships that exist; practices that prevail; beliefs, points of views, or attitudes that are held; processes that are going on; effects that are being felt; or trends that are developing [3]. At times, descriptive research is concerned with how what is or what exists is related to some preceding event that has influenced or affected a present condition or event."

Such studies look at individuals, groups, institutions, methods and materials in order to describe, compare, contrast, classify, analyze and interpret the entities and the events that constitute their various fields of inquiry. Survey gathers data on a one-shot basis, represents a wide target population, generates numerical data, provides descriptive, inferential and explanatory information, gathers standardized information (i.e. using the same instruments and questions for all participants), makes generalizations about, and observes patterns of response in, the targets of focus, and gathers data which can be processed statistically. [4]

Respondents of the survey were 12 managers and 85 employees who were conveniently selected. Thirty (30) conveniently selected customers were also chosen for interview to validate some data gathered based on their perception and observation while on the theme parks. Data were gathered through a standard survey checklist (Sustainable Tourism Practices Checklist released by North Carolina State, USA) [5], interview and by participant observation of researchers. Data were treated using Weighted Mean.

\section{Results and discussion}

\subsection{Green Practices of the Theme Parks}

\section{a. Greenhouse Gas Emission Management and Reduction}

None of the 3 theme parks conduct greenhouse gas emission assessment or carbon footprint analysis. They do not use renewable energy sources like solar energy. They sometimes choose local vendors/suppliers to reduce transportation of items. Only one company institutes fuel economizing programs for company vehicles such as regular inspection of vehicles, reduced idling, and route planning to minimize travel distances. However, they always provide opportunities for the use of alternative forms of transportation for customers and staff such as carpooling and mass transportation.

\section{b. Solid Waste Management: Reduction, Reuse and Recycling}

The three companies install high efficiency air hand-dryers, cloth or roll type to minimize paper towel usage and they always encourage staff to conserve reusable amenities; eliminate use of Styrofoam (polystyrene) and other difficult to recycle products; donate/trade obsolete or unwanted equipment, electronics, furniture, drapes, and carpeting; purchase products, such as condiments, cleaning supplies, and other durable products in bulk and in concentrated form when possible; and use preventative maintenance on equipment to reduce risk of replacement.

They seldom institute reusable methods of informing customers of specials rather than one-time use printed documents, write weekly schedules and prep schedules using reusable products such as a laminate sheet and grease pencil or dry erase board, reuse envelopes for inter-office mail, and ensure that materials such as brochures and marketing materials are printed on paper with high recycled content (at least 35\%) and printed using soy ink. 
The 3 companies never conduct a waste audit/assessment. They do not provide incentives and discounts to customers who use refillable mugs and to-go containers; do not encourage employees to use reusable mugs and cups; do not use purchasing policy to give preference to products that are recyclable, such as toner cartages, and have high post-consumer recycled content; do not institute a composting program for yard and food waste; and do not reduce waste from expired stock by using effective inventory control, such as just-in-time purchasing, effective labelling systems, and last in/first out.

\section{c. Freshwater Consumption Reduction}

They always conduct a water audit with water conservation professionals; conduct regular inspections and establish preventative maintenance schedules to ensure maximum efficiency; use air-cooled refrigeration equipment rather than water-cooled models and only serve water upon request of customers.

They did not install low-flow aerators on sinks and do not use floor cleaning equipment with high pressure, low volume and recycling filtering systems but have installed automatic shut off sinks in common area rest rooms.

\section{d. Wastewater Management}

The three theme parks always ensure proper use, storage, and disposal of cleaning products and other potentially harmful chemicals such as fertilizers and paints; limit the number of chemical products used and stored on the property and have a management plan for chemical purchasing; ensure that all chemicals are securely stored and clearly marked; use environmentally safe/preferable cleaning products; and use environmentally preferable or certified paints, solvents and coatings.

They never use less harmful alternatives if possible such as organic substitutes for chemical fertilizers; use an integrated pest management (IPM) system for interior and exterior pest control; and follow best management practices for fats, oil, and grease.

\section{e. Energy Efficiency, Conservation and Management}

They always turn off electronic equipment at the end of each workday; activate sleep/standby or low energy mode on appliances and computers; replace existing lighting (particularly incandescent) with energy efficient or compact florescent bulbs; perform regularly scheduled preventative maintenance on equipment and appliances, including replacing and cleaning air filters, cleaning burners and air conditioner coils, and checking duct and pipe insulation for damage; purchase and replace existing equipment with energy efficient electronics, appliances, and heating and cooling equipment; insulate facilities, including interior and exterior walls, ceilings, and wall cavities; clean lighting fixtures and lamps regularly to increase illumination; keep appliances and electronics on only when in use; place coolers, refrigerators, and ice machines away from direct sunlight, ovens, and other sources of internal heat; develop a policy to minimize the number of rooms needed to be lit and/or heated/cooled; clean lighting fixtures and lamps regularly to increase illumination; and keep appliances and electronics on only when in use.

\section{f. Ecosystem and Biodiversity Conservation}

The manager and employees of the three theme parks believed that their companies always develop partnerships with local environmental and community organizations; provide environmental education materials and information on local biodiversity conservation efforts to staff and customers; design landscaping or on-site gardens to incorporate and support "heirloom" and native species; work with relevant parks and public land agencies to find out how their business might participate in ecosystem and biodiversity conservation efforts; and provide information on how staff and customers can become involved in community projects such as posting project information in common areas and offer transportation assistance when needed.

The 3 companies sometimes participate in local environmental and conservation efforts either through sponsorship, monetary contributions, or volunteering and supporting employees to do so; provide staff incentives to volunteer and contribute a percentage of annual net revenues to local environmental and community based organizations. 


\section{g. Land Use Planning and Management}

The managers and employees observed that the theme parks always follow standards for development and construction that take into account community values, distinctiveness, and sense of place; adopt development strategies that result in a constructive and collaborative relationship with local community and Subic Bay Metropolitan Authority; and take measures to ensure property and operations do not cause soil loss, soil contamination, or other negative impacts, such as erosion and sediment pollution to lands and waterways.

They admitted that they did not integrate green building design in new construction and remodelling and this is also one comment given by the customers being interviewed.

\section{h. Air Quality Protection}

They always avoid use of ozone depleting chlorofluorocarbons (CFC's) found in refrigerants and aerosols; they designate that their place as a non-smoking establishment or designate smoking areas outside the building and away from air in-take; address the root cause of odors rather than masking them with the use of artificial air cleaners, refreshers, and cleaning products; purchase non-toxic paints or paints with low levels of Volatile Organic Compounds (VOCs).

\section{i. Noise Reduction}

They always maintain "quiet" hours in the evening and early morning for staff and customers and avoid noise intrusion by scheduling service and repairs at optimum hours. They never observed that landscaping design should include a noise abatement plan and place insulation around loud equipment.

\section{j. Responsible Purchasing}

The ones in-charge of purchasing were interviewed and they said that they always develop an environmentally preferable procurement/purchasing program where they give preference to vendors and suppliers that are environmentally and socially responsible, provide recyclable or compostable materials and products come from sustainable and/or renewable sources.

They sometimes purchased recycled and/or environmentally certified building materials on property; regularly test new environmentally preferable products for effectiveness in operations and evaluate current products used and ensure that life-cycle analysis is conducted for major investments such as new equipment and construction projects

\subsection{Preserving the Social Norms and Cultures of Local and Indigenous Communities as well as Providing Economic Benefits}

The managers admitted during the interview that they never develop methods of establishing dialogue with local representatives to determine socio-cultural and economic impacts of their organization and to ensure their concerns are recognized in operational decisions. They also never train staff to ensure they are well-informed on local customs; make their property available for community events

As observed by the researchers and by the customers, the theme parks develop informative educational materials for customers about the local community and local history; use appropriate and authentic cultural elements from the local region; establish policies that restrict commercialization of endangered or protected flora and fauna; incorporate traditional local arts and crafts in your facility and make information available to customers

In terms of economic benefits, the managers and employees always provide information to and encourage customers to purchase local products and services; provide employment opportunities for local community members; allow local artists to display and sell their handicrafts and art work; provide information to customers on local attractions and cultural activities

In the interview with the managers, they involve their companies in some local philanthropic projects and develop a public relations plan that ensures customers, the greater community, and interest groups and others can are aware of your community involvement. They sometimes provide volunteer opportunities for customers and staff and provide promotional information on local services and businesses to customers.

They always ensure that minimum local standards for employee's wages, salaries and benefits, ensuring a livable working wage are given. Experience has shown that tourism often fails to generate local economic benefits when local guides are underutilized. Tour companies and hotels tend not to use local guides. In some 
countries and in specific protected areas, they are required to use under-skilled local guides, which they often see as a financial drain. [6]

\subsection{Training and Education for Employees and Customers}

The managers said in the interview that their companies participate in an environmental or sustainable tourism certification program but do not have a comprehensive environmental plan that includes stakeholder participation and input but they place informational signing about their organization's sustainable practices in appropriate places. They do not provide an incentive program for staff and customers to participant in their business's' current sustainable practices although notification about sustainable efforts is provided to customers in publications, advertising, and web site.

They always offer feedback or comment cards to get customers and staff input on further sustainable practices; educate other businesses about sustainability by speaking at events and conferences and providing tours of facility's sustainable practices. They sometimes provide continuing sustainability training for staff and forums for staff input but never include sustainability as part of staff evaluation.

\subsection{Implications Towards Tourism Sustainability of SBFZ}

While tourism can contribute to the protection and restoration efforts of the environment and its natural resources, the right balance between economic gain and undesirable impacts can be elusive. Managers know that a tourist attraction like theme parks in SBFZ must be periodically renewed, monitored and evaluated to remain competitive in its business operations as well as on its environmental compliance.

A related trend is that, before they travel, many tourists inform themselves about environmental problems and conditions at individual sites. They want destinations to be clean and environmentally sound. Tourists will avoid places that are perceived to fall short of this image. Environmental degradation can lead not only to declining tourism rates but also to changes in the types of tourists that travel to a site.

Because tourists are more environment-conscious of, and interested in, the protection of the natural, historical, cultural and social environment, it will be increasingly important to inform tourists and tour operators, through site interpretation and promotional activities, of the efforts that management is making to maintain the site conducive, safe and environmentally-healthy . Collaborative efforts of all owners, employees and stakeholders must be ensured in institutionalizing green practices in their business operations.

\section{Conclusions}

Findings reveal that the theme parks comply with the minimum environmental requirements but still need to enhance green practices in terms of greenhouse gas reduction, solid wastes management, freshwater consumption reduction, waste water management, energy conservation, biodiversity and ecosystem conservation, land use planning and management, providing economic benefits and preserving the social norms and cultures of local communities, and environmental training and education of employees.

The theme parks develop informative educational materials for customers about the local community and local history; use appropriate and authentic cultural elements from the local region; establish policies that restrict commercialization of endangered or protected flora and fauna; incorporate traditional local arts and crafts in your facility and make information available to customers. In terms of economic benefits, the managers and employees always provide information to and encourage customers to purchase local products and services; provide employment opportunities for local community members; allow local artists to display and sell their handicrafts and art work; provide information to customers on local attractions and cultural activities. The managers said in the interview that their companies participate in an environmental or sustainable tourism certification program but do not have a comprehensive environmental plan that includes stakeholder participation and input but they place informational signing about their organization's sustainable practices in appropriate places. They do not provide an incentive program for staff and customers to participant in their business's' current sustainable practices although notification about sustainable efforts is provided to customers in publications, advertising, and web site.

\section{Acknowledgement}

The author acknowledges the BS Tourism Management students of the College of Business and Accountancy, Columban College for collecting the data used in this study; and the administration of CC for funding support. 


\section{References}

[1] Pedersen, A. (2002). Managing Tourism at World Heritage Sites: A Practical Manual for World Heritage Site Managers. UNESCO World Heritage Centre. URL:http://www.uneptie.org/tourism/home.html

[2] Kothari, C. R. (2004). Research Methodology: Methods and Techniques. New Delhi: New Age International Limited Publisher

[3] Best, J.W. (1970). Research in Education. Englewood Cliffs, NJ: Prentice-Hall.

[4] Cohen, L., Manion, L. and Morrison, K. (2000). Research Methods in Education. London: Routledge Falmer

[5] Sustainable Tourism Practices Checklist for the Tourism Industry. Center for Sustainable Tourism. State of North Carolina, USA

[6] Wood, M. E. (2002). Ecotourism: Principles, Practices \& Policies for Sustainability. United Nations Environment Programme Publication ISBN: 92-807-2064-3, 2002. 